\title{
Decay Management Model for Perishable Goods
}

\author{
P. Sudam Sekhar, Parthiban. S, V.R.K. Murthy
}

\begin{abstract}
Inventory management becomes a challenge when it comes to perishable goods. In practice managing perishable goodsis a difficult task worldwide.Improvement of inventory control of perishable goods depends on the model chosen or implemented. This paper proposes how to improve the profit and to reduce the risk of spoiling the goods with respect to the rate of decay which may be fixed or variable. By considering a specific type of perishable goods this experimental investigation has been done based on linear decay and exponential decay. It has been observed that irrespective of the type of decay, the energy level in forward approach is far better than the back approach of consuming the perishable goods.
\end{abstract}

Key words: Perishable, fixed decay, variable decay, optimization.

\section{INTRODUCTION}

The items which have fixed lifetime are called perishable items. Lifetime in the sense the time after which items are not be useful for consumption. That is the reason perishable items like fruits and vegetables need more care and attention towards the management of inventory. Moreover these products have some special characteristics like rise and fall in demand, less and uncertain life time and customer view towards the quality and durability of the products which makes the inventory different than the nonperishableproduct[1-7].

Taparia, Rajashree et al [8] has discussed the model predictive control strategy to minimize the shortage cost and maximize the profit by formulating the cost function in optimum way, also to derive the replenishment control law MPC strategy has been used.

Taleizadeh et al.[9] described zero lead time and appropriate inventory and pricing policies of a decaying item. The model considered deterioration rate which depends on time as well as constant and demand rate is price-sensitive. A shipment group dispatching policy is also used to dispatch the goods.

Ketzenberg $\mathrm{M}$ et al.[10]demonstrate how to set expiration dates for perishable products using macrov decision process in the context of a retailer that sells a random lifetime product under periodic review.

Agi, Maher AN et al[11] discussed a model to optimize the pricing and inventory control of perishable goods by considering deterioration rate and freshness condition parameter where the demands of the product depends.

Revised Manuscript Received on December 15, 2019 for Science, Technology \& Research,

Vadlamudi-522 213, Guntur, Andhra Pradesh, India. e-mail: sudamshekhar@gmail.com

Parthiban. S, Division of Mathematics, Vignan's Foundation for Science, Technology \& Research,

Vadlamudi-522 213, Guntur, Andhra Pradesh, India.

V.R.K. Murthy, Division of Mathematics, Vignan's Foundation for Science, Technology \& Research,

Vadlamudi-522 213, Guntur, Andhra Pradesh, India.
P. Sudam Sekhar, Division of Mathematics, Vignan's Foundation

In this work two types of decay model is considered to show how effectively one can use the perishable products without losing the energy level of the product. Here linear decay and exponential decay has been considered to discuss the deterioration of the product with suitable example and analyzed the fitness value of each product to use it effectively before it get spoiled.

\section{MATHEMATICAL MODELING}

To model this problem let us see the example: 12 fruits are taken from the market to use it for 12 days (one fruit each day). There are three different cases can be observed, in first case the fruits are in good condition, in second case fruits are in moderate conditions and in third case fruits are in bad condition. As per the condition and appearance of the fruits a fitness value has been to each fruit which ranges between 0 to100. 0 stands for completely spoiled and 100 stands fora fresh fruit.As per the above three cases the fitness values are given accordingly.

Case 1: 97,95,91,90,86,85,82,78,72,69,62,60.

Case 2: 94,90,85,76,65,61,55,45,40,37,29,18.

Case 3: 65,58,51,47,42,38,31,24,19,14,09,04.

Since fruits are perishable in nature the quality of fruits reduce day by day based on the decay factor. Hence it is a challenge to the individual to use the fruits effectively to get at most benefit for every situation.

To model the problem, two types of decay have been considered one is linear decay and another is exponential decay. Let us consider that there are ' $n$ ' numbers of perishable resources $x_{1}, x_{2}, x_{3}, \ldots \ldots \ldots . . x_{n}$ of one kind with the fitness values $p_{1}, p_{2}, p_{3}, \ldots \ldots \ldots \ldots p_{n}$. Assume that resources are sorted in descending order such that $p_{i} \geq p_{i-1}, \forall i, i=1,2, \ldots \ldots . n$. One should note that the fitness values are going to reduce gradually as the resources are perishable in nature.Let us consider the unit time as one day and the decay rate is fixed to $r \%$ (Linear decay). Hence every day $r \%$ of the fruit is decayed. In this scenario if a fruit is picked on $\mathrm{m}^{\text {th }}$ day, the fitness value $p_{i}$ decreases $\mathrm{m}$ times of $\mathrm{r} \%$ of $p_{i}$. Similarly in exponential decay the decay rate is calculated based on $r=a(1-0.5)^{x}$. Two different approach has been used to use the fruits effectively one is forward technique and backward technique, in forward moves individual can start using the fruit from best fitness value $p_{i}$ to the lowest fitness value $p_{j}$ and in backward approach it start from lowest fitness value to highest fitness value of the fruit. In this connection a mathematical expression is suggested to compute the total energy by using the concept that then its fitness value will reduce $n-1$ times of their aggregate fitness

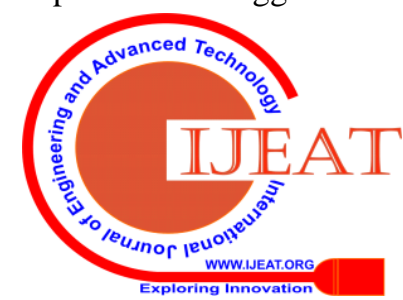


value. The following equations (1) and (2) represents the model for forward and backward technique respectively.

$$
\begin{array}{r}
p_{1}+\left(p_{2}-p_{2} * r \%\right)+\left(p_{3}-p_{3} * 2 r \%\right)+\ldots \ldots \ldots \ldots \ldots \ldots . .+\left(p_{n}-p_{n} *(n-1) r \%\right) \\
p_{n}+\left(p_{n-1}-p_{n-1} * r \%\right)+\left(p_{n-2}-p_{n-2} * 2 \% \%\right)+\ldots \ldots \ldots \ldots \ldots \ldots+\left(p_{1}-p_{1} *(n-1) r \%\right)
\end{array}
$$

\section{EXPERIMENTAL STUDY}

Based on the linear and exponential decay a model has been developed and calculated the energy level of each goods in forward and backward condition. For each case the decay factor is studied and ftness value is changed acording to it.Allow the Apples to consume up using both forward and backward technique.

Case 1: Almost all the apples are in quiet good condition hence utility fitness value of each Apple is given based on these criteria. From Table-1, it is found that the average of fitness value in forward strategy is 15.81 , while the average of fitness value in backward technique is 10.79 using exponential decay.

Case-2: Almost all the apples are in normal condition and the fitness value of each apple is also given accordingly. Based on linear decay from Table-2, it is found that the average of fitness value forward strategy is 14.62 , while the average of fitness value in backward technique is 3.78 .

Case-3: Almost all the apples are in terrible condition and the relating utility fitness values of every apple is given accordingly. Using exponential decay Table-3, it is found that the average of forward strategy is 9.16 , while the average of in backward technique is 1.66 .

From table-1, table 2 and table 3, it is observed that, forward technique is constantly superior to backward technique. Further from fig-1 and Fig-2, it is also observed that in linear decay and exponential decay the forward technique is superior to backward technique.

Table-1 Exponential Decay

\begin{tabular}{|c|c|c|}
\hline Day & Forward & Backward \\
\hline 1 & 98 & 0.04785 \\
\hline 2 & 47.5 & 0.09277 \\
\hline 3 & 22.5 & 0.1758 \\
\hline 4 & 11.25 & 0.3516 \\
\hline 5 & 5.438 & 0.6797 \\
\hline 6 & 2.656 & 1.328 \\
\hline 7 & 1.266 & 2.531 \\
\hline
\end{tabular}

\begin{tabular}{|c|c|c|}
8 & 0.6172 & 4.938 \\
\hline 9 & 0.293 & 9.375 \\
\hline 10 & 0.1367 & 17.5 \\
\hline 11 & 0.06348 & 32.5 \\
\hline 12 & 0.0293 & 60 \\
\hline & \multicolumn{2}{|c|}{ Average } \\
\hline & 15.81 & 10.79 \\
\hline
\end{tabular}

Table-2 Linear Decay

\begin{tabular}{|c|c|c|}
\hline Day & Forward & Backward \\
\hline 1 & 95 & 0.04639 \\
\hline 2 & 45 & 0.08789 \\
\hline 3 & 18.75 & 0.1465 \\
\hline 4 & 9.375 & 0.293 \\
\hline 5 & 4.063 & 0.5078 \\
\hline 6 & 2.031 & 1.016 \\
\hline 7 & 0.7031 & 1.406 \\
\hline 8 & 0.3125 & 2.5 \\
\hline 9 & 0.1367 & 4.375 \\
\hline 10 & 0.05859 & 7.5 \\
\hline 11 & 0.02441 & 12.5 \\
\hline 12 & 0.00732 & 15 \\
\hline & \multicolumn{3}{|c|}{ Average } \\
\hline & 14.62 & 3.782 \\
\hline
\end{tabular}

\begin{tabular}{|c|c|c|}
\hline Day & Forward & Backward \\
\hline 1 & 60 & 0.0293 \\
\hline 2 & 27.5 & 0.05371 \\
\hline 3 & 12.5 & 0.09766 \\
\hline 4 & 5.625 & 0.1758 \\
\hline 5 & 2.5 & 0.3125 \\
\hline 6 & 1.094 & 0.5469 \\
\hline 7 & 0.4688 & 0.9375 \\
\hline 8 & 0.1953 & 1.563 \\
\hline 9 & 0.07813 & 2.5 \\
\hline 10 & 0.0293 & 3.75 \\
\hline 11 & 0.009766 & 5 \\
\hline 12 & 0.002441 & 5 \\
\hline & \multicolumn{2}{|c|}{ Average } \\
\hline & 9.16 & 1.66 \\
\hline
\end{tabular}

Table-3, Exponential decay 


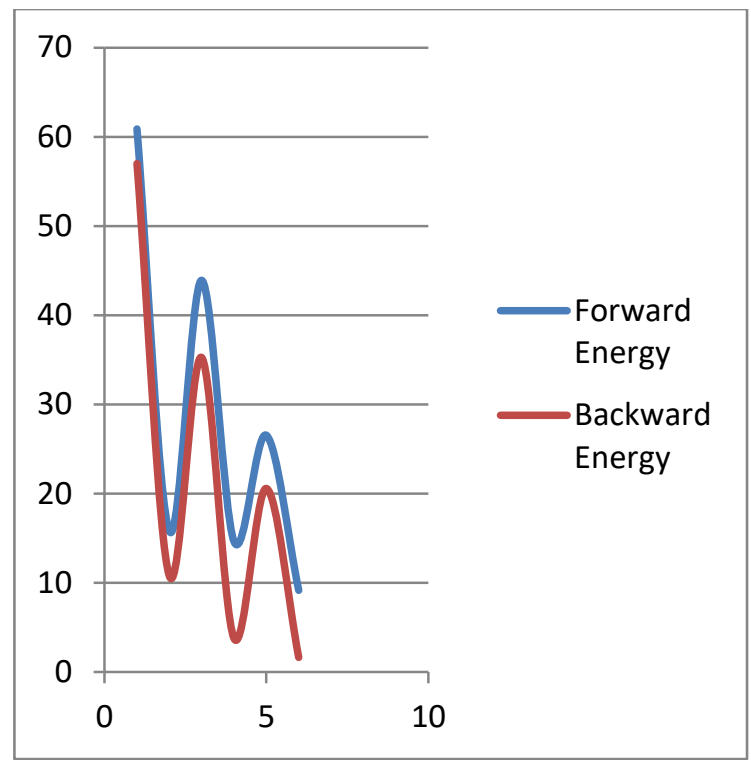

\section{Fig-1: Average fitness value of forward and Backward Method with Linear Decay}

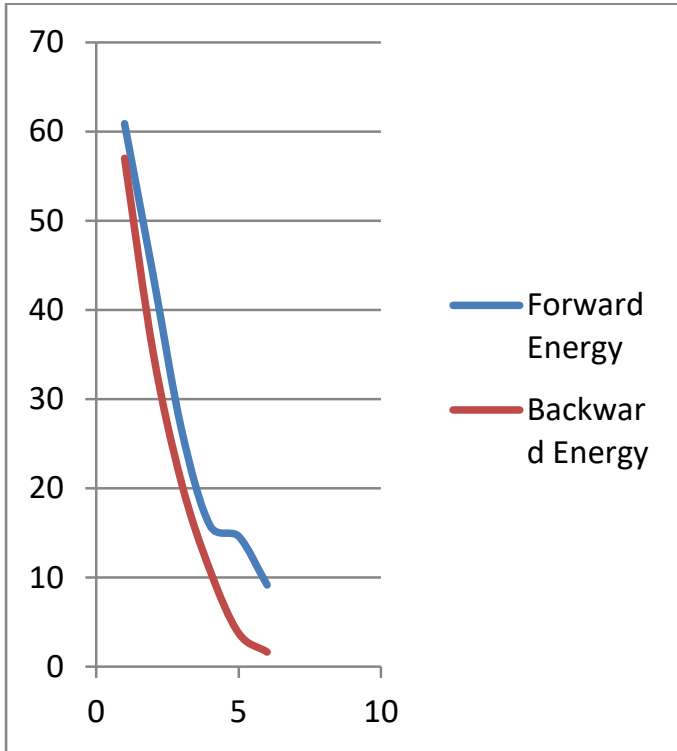

\section{Fig-2: Average fitness value of forward and Backward Method with Exponential Decay.}

\section{CONCLUSION}

In this work an unique idea of consuming the perishable good is presented and solve some conventional issues faced by the consumer and domestic users and to keep the quality of consumable perishable resources like vegetables, fish and chemicals etc. A comparative work is done with linear and exponential decay of perishable goods with two different approach like forward and backward approach and observed that to gain a good amount of energy level forward approach is better than the backward approach $[12,13]$. The principal drawback of the proposed work is that in forward approach the fitness value of some goods may vanish before the consumer get the benefit whereas in back ward approach all the goods can be utilized but with less fitness value.

\section{REFERENCES}

1. Ahumada, O., Vilalobos, J.R.: Operational model for planning the harvest and distribution of perishable agricultural products. Int. J. Prod. Econ. 133(2), 677-687 (2011).

2. Mankiw, N. G.: Principles of Economics, $5^{\text {th }}$ edn. South-Western College Publishing, Boston (2008).

3. McConnell, C.R., Brue, S.L., Flynn, S.M.: Economics: Principles, Problems, and Policies, 19th edn. New York, McGraw-Hill (2011).

4. Miller, G.T., Spoolsman, S.: Living in the Environment: Principles, Connections, andSolutions, 17th edn. Brooks Cole (2011).

5. Mohapatra, Prabhujit, and Santanu Roy.: "Mathematical Model for Optimization of Perishable Resources with Uniform Decay." Computational Intelligence in Data Mining-Volume 2. Springer India, (2016) 447-454.

6. Morley, D.: Understanding Computers: Today and Tomorrow, 13th edn. Stamford, CourseTechnology (2010).

7. Kurniawan, M., I. Santoso, and M. A. Kamal. "Risk management of shallot supply chain using failure mode effect analysis and analytic network process (case study in Batu, East Java)." IOP Conference Series: Earth and Environmental Science. Vol. 230. No. 1. IOP Publishing, 2019.

8. Taparia, Rajashree, S. Janardhanan, and Rajeev Gupta. "Inventory control for nonperishable and perishable goods based on model predictive control." International Journal of Systems Science: Operations \& Logistics (2019): 1-13.

9. Taleizadeh, A. A., and A. Rasuli-Baghban. "Pricing and lot sizing of a decaying item under group dispatching with time-dependent demand and decay rates." Scientia Iranica. Transaction E, Industrial Engineering 25.3 (2018): 1656-1670.

10. Ketzenberg, Michael, Gary Gaukler, and Victoria Salin. "Expiration dates and order quantities for perishables." European Journal of Operational Research 266.2 (2018): 569-584

11. Agi, Maher AN, and Hardik N. Soni. "Joint pricing and inventory decisions for perishable products with age-, stock-, and pricedependent demand rate." Journal of the Operational Research Society (2019): 1-15.

12. Parthiban, S., Gajivaradhan, P.: Statistical Hypothesis Test in Three Factor ANOVA Model Under Fuzzy Environments Using Trapezoidal Fuzzy Numbers, Bulletin of Mathematical Sciences and Applications, Vol. 14 (2016), pp. 23-42

13. Wang, X., Li, D.: A dynamic product quality evaluation based pricing model for perishable food supply chains. Omega 40(6), 906917 (2012). 